Prepared for the U.S. Department of Energy under Contract DE-AC05-76RL01830

\title{
Methods to Collect, Compile, and Analyze Observed Short-lived Fission Product Gamma Data
}

$\begin{array}{llll}\text { EC Finn } & \text { RF Payne } & \text { LR Greenwood } & \text { BD Pierson } \\ \text { LA Metz } & \text { JI Friese } & \text { JD Kephart } & \text { TA Ellis }\end{array}$

September 2011

Pacific Northwest

NATIONAL LABORATORY

Proudly Operated by Battelle Since 1965 


\title{
DISCLAIMER
}

This report was prepared as an account of work sponsored by an agency of the United States Government. Neither the United States Government nor any agency thereof, nor Battelle Memorial Institute, nor any of their employees, makes any warranty, express or implied, or assumes any legal liability or responsibility for the accuracy, completeness, or usefulness of any information, apparatus, product, or process disclosed, or represents that its use would not infringe privately owned rights. Reference herein to any specific commercial product, process, or service by trade name, trademark, manufacturer, or otherwise does not necessarily constitute or imply its endorsement, recommendation, or favoring by the United States Government or any agency thereof, or Battelle Memorial Institute. The views and opinions of authors expressed herein do not necessarily state or reflect those of the United States Government or any agency thereof.

\author{
PACIFIC NORTHWEST NATIONAL LABORATORY \\ operated by \\ BATTELLE \\ for the \\ UNITED STATES DEPARTMENT OF ENERGY \\ under Contract DE-AC05-76RL01830 \\ Printed in the United States of America \\ Available to DOE and DOE contractors from the \\ Office of Scientific and Technical Information, \\ P.O. Box 62, Oak Ridge, TN 37831-0062; \\ ph: (865) 576-8401 \\ fax: $(865) 576-5728$ \\ email: reports@adonis.osti.gov \\ Available to the public from the National Technical Information Service \\ 5301 Shawnee Rd., Alexandria, VA 22312 \\ ph: (800) 553-NTIS (6847) \\ email: orders@ntis.gov <http://www.ntis.gov/about/form.aspx> \\ Online ordering: http://www.ntis.gov
}




\title{
Methods to Collect, Compile, and Analyze Observed Short-lived Fission Product Gamma Data
}

\author{
EC Finn \\ LR Greenwood \\ LA Metz \\ JD Kephart \\ RF Payne \\ BD Pierson \\ JI Friese \\ TA Ellis
}

January 2011

Prepared for

the U.S. Department of Energy

under Contract DE-AC05-76RL01830

Pacific Northwest National Laboratory

Richland, Washington 99352 


\section{Summary}

A unique set of fission product gamma spectra was collected at short times ( 4 minutes to 1 week) on various fissionable materials. Gamma spectra were collected from the neutron-induced fission of uranium, neptunium, and plutonium isotopes at thermal, epithermal, fission spectrum, and 14-MeV neutron energies. This report describes the experimental methods used to produce and collect the gamma data, defines the experimental parameters for each method, and demonstrates the consistency of the measurements. 



\section{Acronyms}

$\begin{array}{ll}\text { DSM } & \text { direct simultaneous measurement } \\ \text { HPGe } & \text { high purity germanium } \\ \text { IBI } & \text { International Bio-Analytical Industries } \\ \text { IPL } & \text { Isotope Products Laboratories } \\ \text { MCNP } & \text { Monte Carlo N-Particle (transport code) } \\ \text { NBL } & \text { New Brunswick Laboratory } \\ \text { ORNL } & \text { Oak Ridge National Laboratory } \\ \text { PNNL } & \text { Pacific Northwest National Laboratory } \\ \text { WSU } & \text { Washington State University }\end{array}$





\section{Acknowledgements}

This work was supported by NA-22, Office of Nuclear Detonation Detection, Nonproliferation and Verification Research and Development, National Nuclear Security Administration, U.S. Department of Energy. We thank Jessica Drader, C. Corey Hines, Mat King, and Don Wall of the Dodgen Research Facility and Nuclear Radiation Center at Washington State University for their assistance with the neutron irradiations. Pacific Northwest National Laboratory is operated by Battelle for the U.S. Department of Energy under Contract DE-AC05-76RL01830. 



\section{Contents}

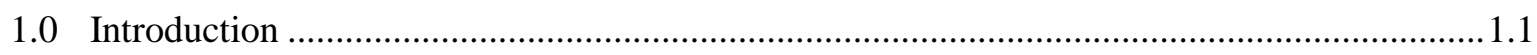

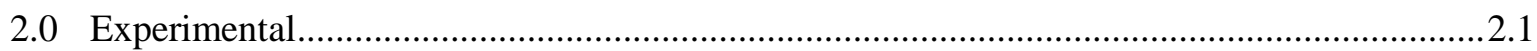

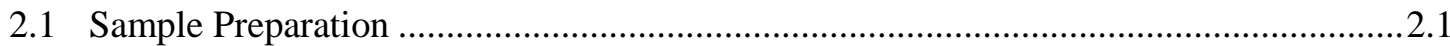

2.1.1 Thermal, Epithermal, and Fission Energy Neutron Samples .............................2.1

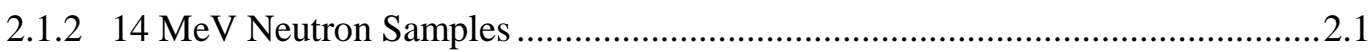

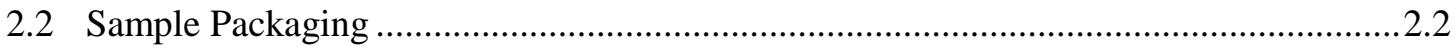

2.2.1 Thermal Neutron Spectrum Data ...............................................................2.2

2.2.2 Epithermal Neutron Spectrum Data _..............................................................2.3

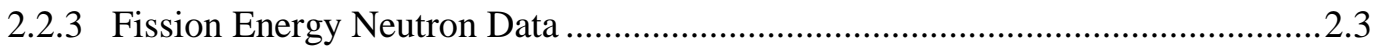

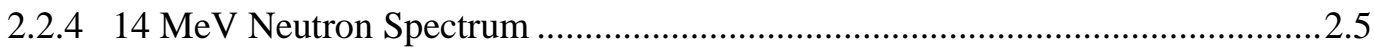

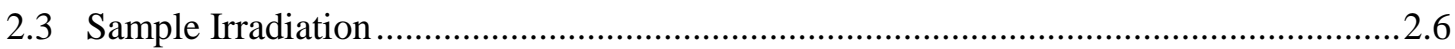

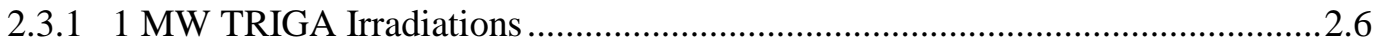

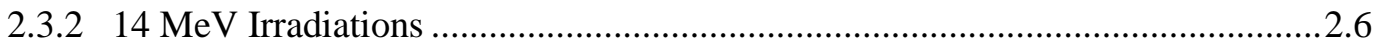

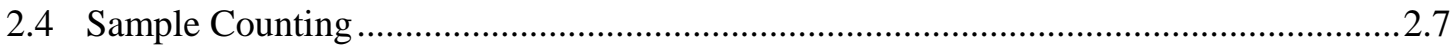

2.4.1 Gamma Acquisition by High Purity Germanium Detector at WSU ....................2.7

2.4.2 Gamma Acquisition by High Purity Germanium Detector at PNNL ...................2.8

2.4.3 Gamma Acquisition by Direct Simultaneous Measurement at PNNL .................2.8

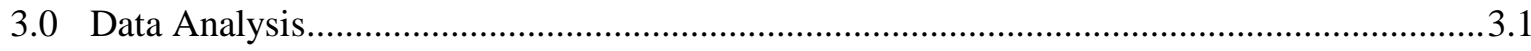

3.1 Neutron Fluence Monitors and Observed Spectrum .................................................... 3.1

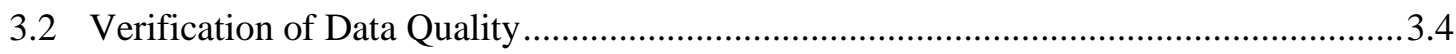

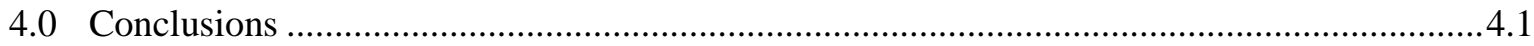

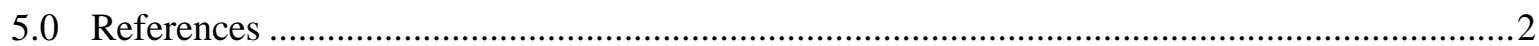


PNNL-20141

\section{Figures}

Figure 2.1. Sample Preparation. Sample is drying onto filter...................................................2.2

Figure 2.2. Cross-Sectional Schematic of the $\mathrm{B}_{4} \mathrm{C}$ Capsule ......................................................... 2.4

Figure 2.3. $\mathrm{B}_{4} \mathrm{C}$ Shield Sealed in Plastic Before Irradiation .....................................................2.5

Figure 2.4. Custom-Fabricated Polyethylene Containment Used for $\mathrm{B}_{4} \mathrm{C}$ Irradiations .................2.5

Figure 2.5.A) Photograph of the $14 \mathrm{MeV}$ Generator Used for Experiments. B) Sample Positioned on the

$14 \mathrm{MeV}$ Generator Perpendicular to the Target Plane (4.5 inches from the front of the tube).2.7

Figure 3.1. Adjusted STAY'SL Model of Neutron Spectrum Within the WSU Core....................3.3

Figure 3.2. Adjusted STAY'SL Model for $14 \mathrm{MeV}$ Neutron Generator........................................3.3

Figure 3.3. Measured Fission Yields in Fission Energy Neutron Experiments ................................ 3.4

Figure 3.4. Measured Fission Yields in 14-MeV Experiments with ${ }^{238} \mathrm{U}$.......................................5

Figure 3.5.Decay-Corrected Counts to Time Zero of ${ }^{91} \mathrm{Sr}\left(\mathrm{t}_{1 / 2}=9.5 \mathrm{~h}\right)$ and ${ }^{92} \mathrm{Sr}\left(\mathrm{t}_{1 / 2}=2.7 \mathrm{~h}\right)$ at Various Times After Irradiation of ${ }^{235} \mathrm{U}$ Under Boron Carbide............................................................. 3.6

Figure 3.6.Example of Data Consistency for ${ }^{239} \mathrm{Pu}$ Fission Spectrum Irradiation. Blue diamonds are data collected at WSU immediately after the pulse, with the blue line being the average. Red triangles are data collected after transport to PNNL, with the red line being the average.

\section{Tables}

Table 1.1. Short-Lived Fission Product Experiments Completed................................................ 1.1

Table 2.1. Sample Information for Each Fission Experiment.....................................................2.2

Table 2.2. Approximate Masses of Fluence Wires Used in Each Set of Experiments ..................2.3

Table 2.3. Approximate Masses of Fluence Wires Used in $14 \mathrm{MeV}$ Neutron Experiments...........2.6

Table 3.1. Activation Reactions Observed for Calculation of Neutron Spectrum ........................... 3.1

Table 3.2. Ranges of Fluence Values Observed in Each Neutron Spectrum .................................3.1

Table 3.3. Example of Observed Neutron Fluence for Cd-Shielded 14-MeV Experiments............3.2 


\subsection{Introduction}

Experiments involving the neutron irradiation of various actinides and subsequent fission product measurements have traditionally been conducted at times greater than 5 days, resulting in the analysis of fission products with half-lives in the range of 1 day to 30 years following chemical separations.

Interpreting gamma spectra on samples of unseparated shorter-lived fission products (radionuclides with half-lives ranging from $75 \mathrm{~s}$ to 3 days) is not as well understood because of the complexity of these spectra and the limited availability of experimental spectra containing the full suite of fission products at these half-lives. Modeling of gamma spectra is thus frequently used to deduce information about shortlived nuclear data. A goal of this work was to compile a set of fission-product gamma data at short times on various fissionable materials.

This report describes the methods used to collect, compile, and analyze the set of short-lived fissionproduct gamma data. The experimental procedure used to collect fission-product data from the neutroninduced fission of uranium, neptunium, and plutonium at four different energy bins (Table 1.1) is outlined in this report. Experiments with thermal, epithermal, and fission energy neutrons were completed at the Washington State University (WSU) TRIGA reactor by irradiating the samples bare, cadmium shielded, and boron carbide shielded, respectively. High neutron energy (14-MeV) experiments were completed at Pacific Northwest National Laboratory (PNNL) with a D-T 14-MeV neutron generator. Samples were counted on a standard high purity germanium (HPGe) detection system as well as an advanced coincidence system, starting at 4 minutes post irradiation and continuing for up to 1 week.

It is important to preserve these data in such a way that they are available for public use for various nuclear physics or chemistry applications. This report describes the experimental parameters and methods used to verify the consistency of the data. This knowledge facilitates understanding and use of the data set. Detailed information about neutron energy ranges and fluences used for each experiment is provided. A brief description of how short-lived isotopes were measured in the complicated gamma spectra is also provided in this report.

Table 1.1. Short-Lived Fission Product Experiments Completed

\begin{tabular}{ccccc}
\hline Samples & Thermal & Epithermal & Fission Spectrum & $14 \mathrm{MeV}$ \\
\hline${ }^{233} \mathrm{U}$ & $\checkmark$ & $\checkmark$ & $\checkmark$ & \\
${ }^{235} \mathrm{U}$ & $\checkmark$ & $\checkmark$ & $\checkmark$ & $\checkmark$ \\
${ }^{238} \mathrm{U}$ & & $\checkmark$ & $\checkmark$ & \\
${ }^{237} \mathrm{~Np}$ & & $\checkmark$ & $\checkmark$ & \\
${ }^{239} \mathrm{Pu}$ & $\checkmark$ & $\checkmark$ & $\checkmark$ & \\
\hline
\end{tabular}


PNNL-20141

\subsection{Experimental}

\subsection{Sample Preparation}

\subsubsection{Thermal, Epithermal, and Fission Energy Neutron Samples}

Working solutions containing known concentrations of the radionuclides ${ }^{233} \mathrm{U},{ }^{235} \mathrm{U},{ }^{238} \mathrm{U},{ }^{237} \mathrm{~Np}$, and ${ }^{239} \mathrm{Pu}$ individually at $>97 \%$ isotopic purity were prepared. The stock materials came from isotopic standards listed in Table 2.1, except for the materials for the $14 \mathrm{MeV}$ experiments that are described below. The sample matrix was less than or equal to $2 \mathrm{M}$ nitric acid. Nitric acid was used to minimize formation of activation products during irradiation. Other matrices such as hydrochloric acid can result in significant activation that interferes with the gamma spectra collected. The mass of sample used in each case is given in Table 2.1, where the mass of sample was calculated to produce approximately $1 \times 10^{8}$ fissions from a pulse of a 1 MW TRIGA reactor.

In order to avoid cross-contamination, supplies used for sample preparation were leached using an 8 $\mathrm{M} \mathrm{NH}_{4} \mathrm{OH} / 8 \mathrm{M} \mathrm{HNO}_{3}$ procedure prior to use. In addition, sample preparation and packaging for irradiation were done in a clean environment. Samples of each isotope were prepared in triplicate. A gravimetric aliquot of each working solution was placed into a vial and transposed to a few microliters of $2 \mathrm{M} \mathrm{HNO}_{3}$. Whatman ashless filters were cut to $8 \mathrm{~mm}$ using a hole boring tool. The transposed solution was added to the filter in $0.5 \mu \mathrm{L}$ aliquots and dried under a heat lamp after each addition to keep the deposited material as concentrated as possible. Complete transfer of the material was ensured by rinsing the vial with a few microliters of $<2 \mathrm{M} \mathrm{HNO}_{3}$ and adding to the filter in the same fashion as the sample. It is important to use a moderate concentration of nitric acid to be sure that quantitative transfer is complete while avoiding the fragility of the filter that occurs when higher concentrations are used. When sample loading was complete, each filter was heat-sealed into a Tedlar® sleeve. Tedlar ${ }^{\circledR}$ was used in an effort to retain gaseous fission products, however losses were still observed (discussed below). In Figure 2.1, the sample is shown drying onto the filter.

\subsection{2 $\quad 14 \mathrm{MeV}$ Neutron Samples}

A single sample was prepared from thin foils of $99.998 \%$ pure ${ }^{238} \mathrm{U}$ metal. These foils are circles 0.5 in. in diameter and 0.005 in. thick. Each foil weighs approximately $0.3 \mathrm{~g}$. The foil was laid on a piece of packing tape and a second piece of packing tape was carefully laid over the top and pressed to seal. The excess tape was cut away to leave approximately $3 \mathrm{~mm}$ of tape around the edges of the foil. Multiple foils were stacked to create a larger sample of $1.57 \mathrm{~g}$. Due to the low neutron flux of the D-T generator, the largest sample mass resulted in only $\sim 1.5 \times 10^{7}$ fissions. 
Table 2.1. Sample Information for Each Fission Experiment

\begin{tabular}{|c|c|c|c|c|}
\hline Experiment & Isotopic Standard & $\begin{array}{c}\text { Initial Chemical } \\
\text { Form } \\
\end{array}$ & $\begin{array}{c}\text { Isotopic } \\
\text { Purity }(\%)\end{array}$ & $\begin{array}{c}\text { Average Sample } \\
\text { Mass (g) }\end{array}$ \\
\hline${ }^{233} \mathrm{U}$ Thermal & NBL CRM 111A & $\mathrm{UO}_{2}\left(\mathrm{NO}_{3}\right)_{2}(\mathrm{aq})$ & 99.4911 & $6.80 \mathrm{E}-07$ \\
\hline${ }^{233} \mathrm{U}$ Epithermal & NBL CRM 111A & $\mathrm{UO}_{2}\left(\mathrm{NO}_{3}\right)_{2}(\mathrm{aq})$ & 99.4911 & $2.77 \mathrm{E}-05$ \\
\hline${ }^{233} \mathrm{U}$ Fission & NBL CRM 111A & $\mathrm{UO}_{2}\left(\mathrm{NO}_{3}\right)_{2}(\mathrm{aq})$ & 99.4911 & $5.02 \mathrm{E}-04$ \\
\hline${ }^{235} \mathrm{U}$ Thermal & NBL CRM U970 & $\mathrm{U}_{3} \mathrm{O}_{8}$ & 97.663 & $3.51 \mathrm{E}-07$ \\
\hline${ }^{235} \mathrm{U}$ Epithermal & NBL CRM U970 & $\mathrm{U}_{3} \mathrm{O}_{8}$ & 97.663 & $5.21 \mathrm{E}-05$ \\
\hline${ }^{235} \mathrm{U}$ Fission & ORNL U235-165-AR & $\mathrm{U}_{3} \mathrm{O}_{8}$ & 99.71 & $2.05 \mathrm{E}-03$ \\
\hline${ }^{238} \mathrm{U}$ Epithermal & IBI & $\mathrm{UO}_{2}$ & 99.80 & $2.60 \mathrm{E}-03$ \\
\hline${ }^{238} \mathrm{U}$ Fission & IBI & $\mathrm{UO}_{2}$ & 99.80 & $2.62 \mathrm{E}-03$ \\
\hline${ }^{238} \mathrm{U} 14 \mathrm{MeV}$ & PNNL & Metal foil & 99.998 & 1.57 \\
\hline${ }^{237} \mathrm{~Np}$ Epithermal & PNNL & $\mathrm{NpO}_{2}$ & 99.99 & $9.98 \mathrm{E}-04$ \\
\hline${ }^{237} \mathrm{~Np}$ Fission & PNNL & $\mathrm{NpO}_{2}$ & 99.99 & $1.01 \mathrm{E}-03$ \\
\hline${ }^{239} \mathrm{Pu}$ Thermal & IPL (Lot\# 1195.15) & $\mathrm{Pu}\left(\mathrm{NO}_{3}\right)_{4}$ & 97.937 & $3.55 \mathrm{E}-07$ \\
\hline${ }^{239} \mathrm{Pu}$ Epithermal & PNNL & Metal foil & 99.11 & 4.29E-05 \\
\hline${ }^{239} \mathrm{Pu}$ Fission & PNNL & Metal foil & 99.11 & $7.68 \mathrm{E}-04$ \\
\hline \multicolumn{5}{|c|}{$\begin{array}{l}\text { NBL_-New Brunswick Laboratory } \\
\text { ORNL_-Oak Ridge National Laboratory } \\
\text { IBI-International Bio-Analytical Industries } \\
\text { IPL-Isotope Products Laboratories }\end{array}$} \\
\hline
\end{tabular}

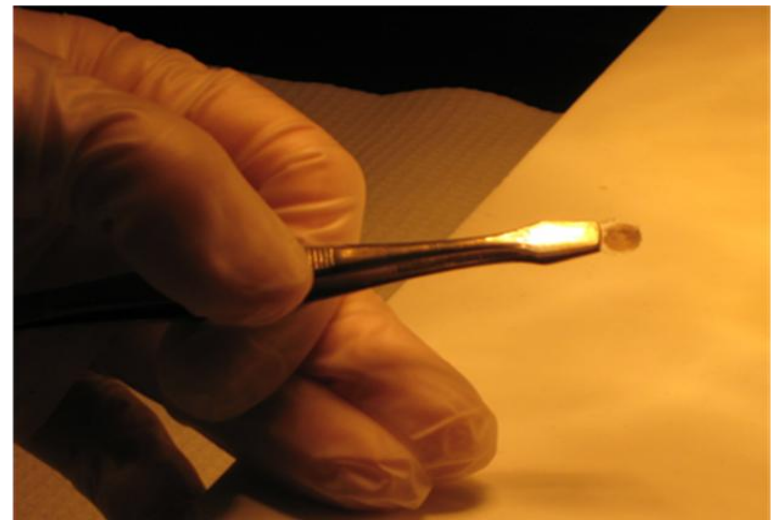

Figure 2.1. Sample Preparation. Sample is drying onto filter.

\subsection{Sample Packaging}

\subsubsection{Thermal Neutron Spectrum Data}

Thermal neutron spectrum data were collected with unshielded samples. The three individual filter papers enclosed in Tedlar ${ }^{\circledR}$ were stacked and pushed into the bottom of a 2/5 dram polyethylene vial. This vial was heat sealed to make sure that the sample and fission products were contained. The neutron fluence varies between reactor pulses and cannot be predicted accurately (Payne et al. 2009); therefore, a series of neutron fluence monitors were irradiated with each sample to quantitatively analyze the neutron 
spectrum. The fluence monitors were composed of high-purity elements and alloys, described in Table 2.2. The wires were placed in the bottom of a second $2 / 5$ dram vial, which was also heat sealed. To ensure that the neutron spectrum obtained from analyzing the fluence monitors was representative of that incident on the samples, the samples and fluence monitors were placed as closely together as possible. This was accomplished by placing the vial containing the samples upside-down into a 2-dram vial. The vial containing the fluence monitors was then placed on top of this, and the 2-dram vial was heat-sealed. The 2-dram vial was then fixed to a rotator assembly using zip ties.

Table 2.2. Approximate Masses of Fluence Wires Used in Each Set of Experiments

\begin{tabular}{|c|c|c|c|}
\hline $\begin{array}{l}\text { Material (purity), } \\
\text { manufacturer }\end{array}$ & $\begin{array}{l}\text { Approximate Mass } \\
\text { Used for Thermal } \\
\text { (unshielded) } \\
\text { Experiments (mg) }\end{array}$ & $\begin{array}{l}\text { Approximate Mass Used } \\
\text { for Epithermal (Cd- } \\
\text { shielded) Experiments } \\
\text { (mg) }\end{array}$ & $\begin{array}{l}\text { Approximate Mass Used } \\
\text { for Fission Spectrum }\left(\mathrm{B}_{4} \mathrm{C}-\right. \\
\text { shielded) Experiments } \\
(\mathrm{mg})\end{array}$ \\
\hline $\mathrm{Cu}(99.999 \%)$, Cominco & 3.6 & 7.7 & 8.7 \\
\hline Fe (99.999\%), MARZ & 121.8 & 125.8 & 156.7 \\
\hline $\begin{array}{l}\mathrm{Ti}(99.917 \%), \text { Reactor } \\
\text { Experiments, Inc. }\end{array}$ & 11.2 & 10.9 & 12.5 \\
\hline $\begin{array}{l}1.0 \% \text { Co-V alloy, Mol } \\
\text { (Fabry) }\end{array}$ & 2.0 & 15.3 & 7.0 \\
\hline $\begin{array}{l}0.135 \% \text { Au-Al alloy } \\
\text { (99.916\%), Reactor } \\
\text { Experiments, Inc. }\end{array}$ & 2.2 & 7.5 & 8.6 \\
\hline
\end{tabular}

\subsubsection{Epithermal Neutron Spectrum Data}

Epithermal neutron spectrum data were collected using cadmium shielded samples. Cadmium shields were $99.95 \%$ pure and were purchased from Reactor Experiments, Inc. The shields measured 1 in. in outer diameter and 0.020 in. thick. The fluence monitors were heat-sealed into a plastic bag and laid in the bottom of the cadmium shield. The fluence monitors are the same materials as were used in the thermal experiments (Table 2.2). The filter papers enclosed in Tedlar ${ }^{\circledR}$ were laid on top of the fluence monitor package. The cadmium shield was closed by lightly crimping the edges by hand and using two narrow strips of $\mathrm{Cd}$ metal wrapped completely around the shield perpendicular to each other. This assembly was then placed in the bottom of an 8-dram vial with a loosely crumpled KimWipe ${ }^{\circledR}$ on top to prevent excessive movement. The vial was heat sealed and fixed to a rotator assembly with zip ties.

\subsubsection{Fission Energy Neutron Data}

Boron is known (McLane et al. 1988; Galy et al. 2000; Turner and Haynes 2009) to absorb thermal and epithermal neutrons, allowing only fission energy neutrons to interact with the sample. Therefore, PNNL designed a boron carbide shield to be used to collect fission energy neutron data. The shield was manufactured by Ceradyne Inc. A cross-sectional schematic of this shield is shown in Figure 2.2. The shield is $5 \mathrm{~cm}$ in diameter and $12 \mathrm{~cm}$ high with a total mass of $577.6 \mathrm{~g}$. It has a male and female side that fit snugly together to form a $1 \mathrm{~cm}$ by $8 \mathrm{~cm}$ cylindrical interior cavity. 
In packaging the samples for irradiation, it is important to ensure that the filters and fluence monitors are in close proximity to one another for the most reliable fluence measurements. Vertical alignment is especially important as the neutron fluence is very sensitive to this parameter. The fluence monitors were heat-sealed into a small plastic bag. To keep the filters and fluence monitors together, the filters in Tedlar® were stacked with the fluence monitor package and slipped into a plastic sleeve. The plastic sleeve containing the filters and fluence monitors is rolled and slipped into the female side of the boron carbide shield. The female side is used to facilitate easier removal of the samples following irradiation.

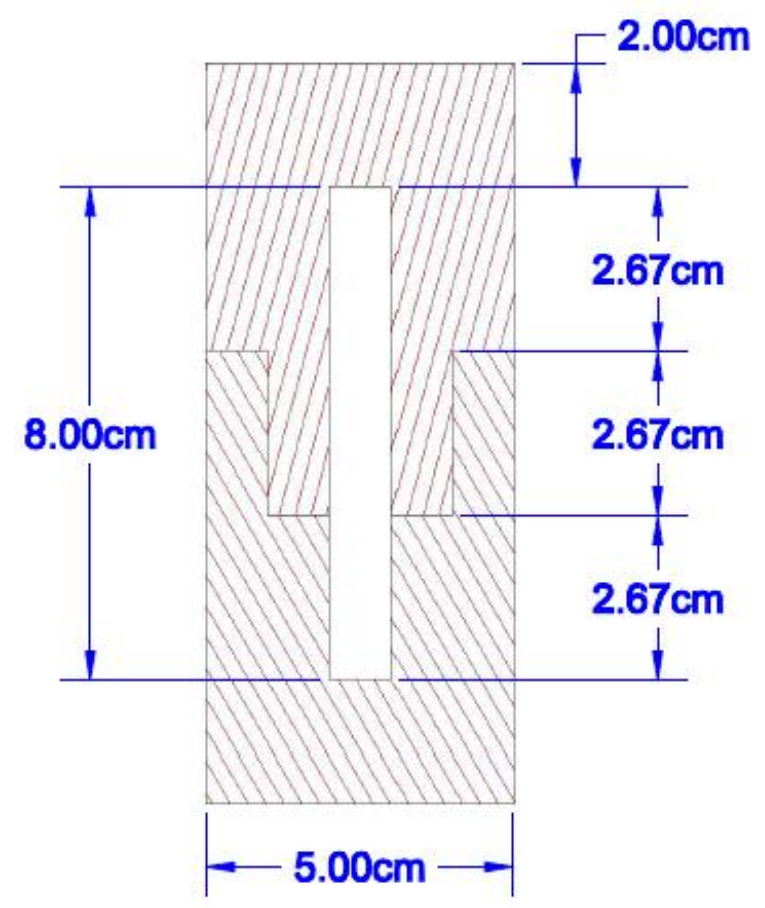

CROSS SECTION

Figure 2.2. Cross-Sectional Schematic of the $\mathrm{B}_{4} \mathrm{C}$ Capsule

The assembled boron carbide shield was heat sealed into a plastic bag (Figure 2.3). The boron carbide was then placed into a polyethylene container custom designed and fabricated at WSU (Figure 2.4), which was sealed with o-rings and zip ties. 


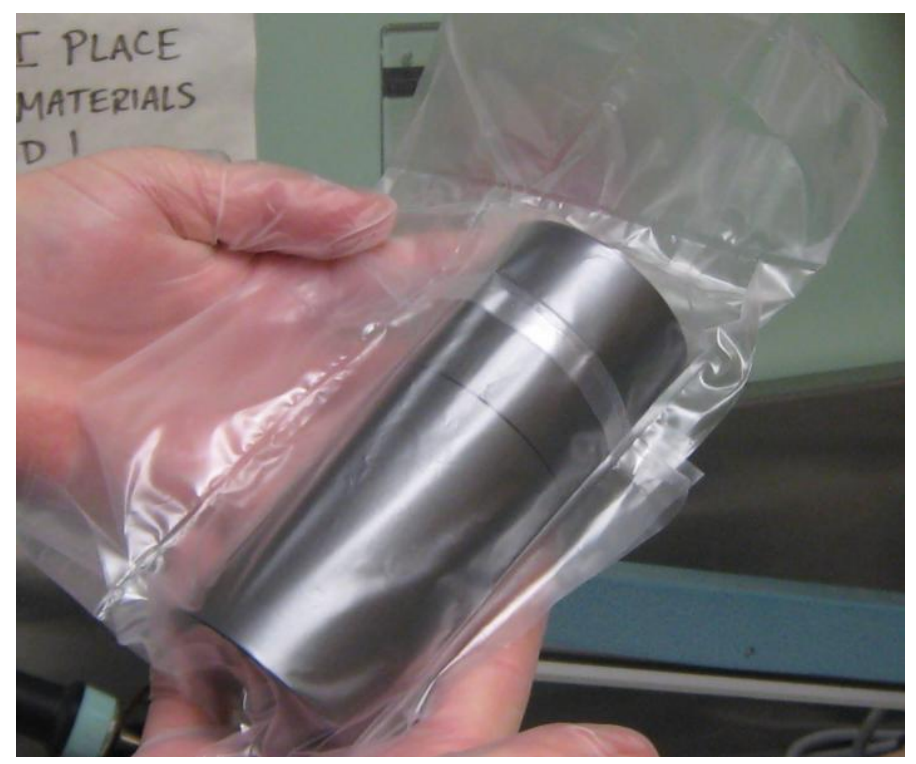

Figure 2.3. $\mathrm{B}_{4} \mathrm{C}$ Shield Sealed in Plastic Before Irradiation

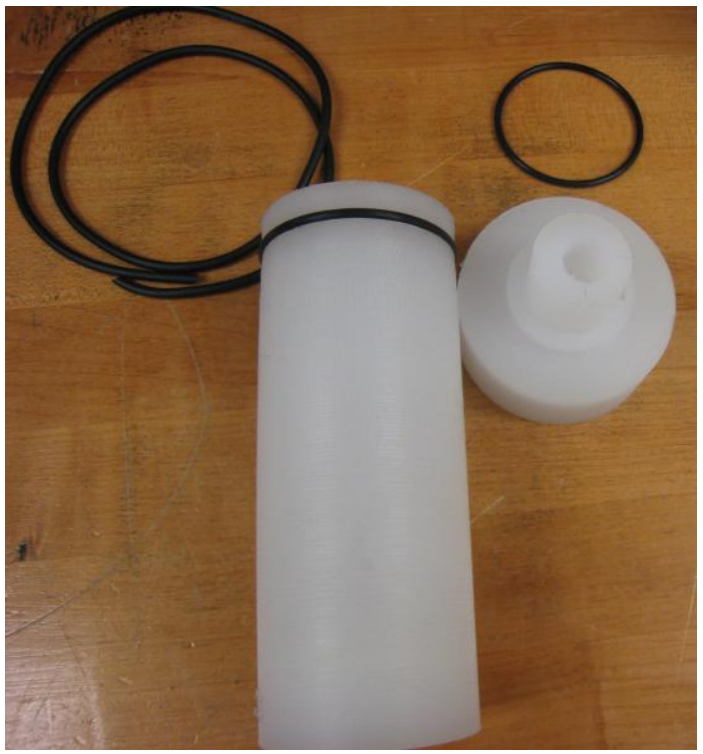

Figure 2.4. Custom-Fabricated Polyethylene Containment Used for $\mathrm{B}_{4} \mathrm{C}$ Irradiations

\subsection{4 $14 \mathrm{MeV}$ Neutron Spectrum}

High-purity fluence foils $0.5 \mathrm{in}$. in diameter were used to measure the neutron spectrum. The materials used are described in Table 2.3. The aluminum foil discs were cut from a metal strip. The foils were stacked in the order $\mathrm{Fe}, \mathrm{Au}, \mathrm{In}, \mathrm{Cu}$, and $\mathrm{Al}$ and heat-sealed into a plastic bag. The $\mathrm{Al}$ was placed directly behind the sample foils inside a Cd shield (as used for the epithermal experiments) to eliminate thermal fissions due to environmental down-scattering of the neutrons. The Cd shield holding the fluence foils and sample was sealed in a plastic bag. 
PNNL-20141

Table 2.3. Approximate Masses of Fluence Wires Used in $14 \mathrm{MeV}$ Neutron Experiments

\begin{tabular}{lcc}
\hline \multicolumn{1}{c}{ Material (purity), manufacturer } & Thickness (in.) & $\begin{array}{c}\text { Approximate Mass Used for } \\
\text { Experiment (mg) }\end{array}$ \\
\hline $\mathrm{Fe}(99.9 \%)$, Reactor Experiments, Inc. & 0.005 & 100 \\
$\mathrm{Au}(99.992 \%)$, Reactor Experiments, Inc. & 0.002 & 100 \\
$\mathrm{In}(99.99 \%)$, Reactor Experiments, Inc. & 0.005 & 200 \\
$\mathrm{Cu}(99.9928 \%)$, Reactor Experiments, Inc. & 0.005 & 100 \\
$\mathrm{Al}$ (99.99\%), Materials Research Corporation & 0.010 & 100 \\
\hline
\end{tabular}

\subsection{Sample Irradiation}

\subsubsection{MW TRIGA Irradiations}

Thermal, epithermal, and fission neutron spectrum irradiations were performed at the 1-MW TRIGA reactor at WSU in Pullman, Washington. For the thermal and epithermal neutron spectrum experiments, the reactor was stabilized at $80 \mathrm{~W}$ before inserting the samples. Samples were placed into position D8 and irradiated for approximately $50 \mathrm{~ms}$ following a 2-dollar reactivity insertion. Samples were immediately removed from the reactor without cooling, resulting in contact dose rates of 50 to $100 \mathrm{mrem} / \mathrm{hr}$ (bare irradiations) and 18 to $39 \mathrm{mrem} / \mathrm{hr}$ (Cd-shielded) upon removal.

Adjustments to the irradiation conditions were required for the fission neutron spectrum experiments. The $\mathrm{B}_{4} \mathrm{C}$ shield was carefully designed and fabricated to ensure reactor safety and correct experimental conditions during use. Prior to fabrication, a piece of the proposed $\mathrm{B}_{4} \mathrm{C}$ material from Ceradyne, Inc. was irradiated at WSU. No interfering impurities were present and the material from Ceradyne, Inc. was deemed suitable for fabricating the shield. It was anticipated that the large mass of the boron carbide could influence the stabilization of the reactor, so the shield was briefly irradiated empty. It was found that reactor power dropped significantly following boron carbide insertion; re-stabilization was required before pulsing the reactor. Based on these results, the reactor was stabilized at $\sim 100 \mathrm{~W}$ prior to insertion of actinide samples. After the sample in the shield was inserted the reactor was re-stabilized within 3-5 minutes to a power of $80 \mathrm{~W}$. Once stabilized, the reactor was pulsed as was done to achieve thermal and epithermal neutron spectra. Samples were removed without cooling and the observed dose rate was 20-34 $\mathrm{mrem} / \mathrm{hr}$ on contact. The neutron fluence to the samples during reactor stabilization was negligible relative to the fluence during the pulse.

\subsection{2 $\quad 14 \mathrm{MeV}$ Irradiations}

Irradiations were conducted at PNNL with a Thermo Scientific P 385 neutron generator. The generator was positioned on an aluminum support in the middle of the laboratory to reduce the down scattering of neutrons (Figure 2.5A). The location of maximum neutron fluence was determined by making neutron fluence measurements at four different locations on the outside of the neutron generator head. The location directly adjacent to the target plane resulted in the highest measured neutron fluence $\left(9.11 \times 10^{11} \mathrm{n} / \mathrm{cm}^{2} \pm 12 \%\right)$. For each experiment, the plastic bag holding the sample and fluence foils was taped to a stainless steel band clamp loosely placed around the target plane of the neutron generator head 
4.5 in. from the front of the generator tube (Figure 2.5B). Each irradiation lasted for 2 hours. Following irradiation, the sample was repackaged and transported as quickly as possible for gamma analysis.
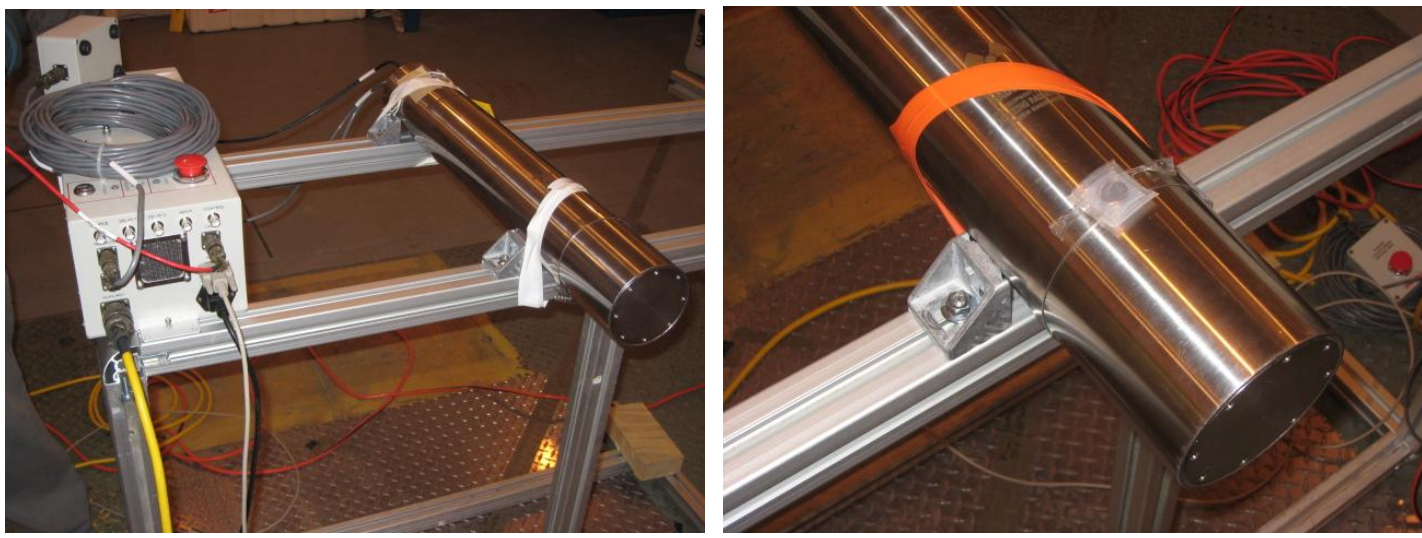

Figure 2.5. A) Photograph of the $14 \mathrm{MeV}$ Generator Used for Experiments. B) Sample Positioned on the $14 \mathrm{MeV}$ Generator Perpendicular to the Target Plane (4.5 inches from the front of the tube).

\subsection{Sample Counting}

The triplicate samples of each isotope were irradiated together for each experiment performed at WSU. One of the replicates was counted beginning 4 minutes after irradiation at WSU using a singlecrystal HPGe detector. The remaining two samples and the fluence monitors were returned to PNNL for counting. From 6 hours to 1 week following the pulse, the second sample was counted at PNNL with a single crystal HPGe detector. The fluence monitors were also analyzed at PNNL with HPGe detection. The third sample was counted on a direct simultaneous measurement (DSM) detector system at PNNL from $\sim 6$ hours to 1 week post-pulse.

Only one sample was irradiated during the $14-\mathrm{MeV}$ neutron spectrum experiments. Gamma acquisition was performed with a single-crystal HPGe detector at PNNL 70 min after completing the irradiation and continuing for up to 1 week. The following sections provide further details about each detection system and methods used for their operation.

\subsubsection{Gamma Acquisition by High Purity Germanium Detector at WSU}

In the first $51 / 2$ - 6 hours following the pulse, 14 total spectra were collected. The count time was always based on live time. Counting began 4 minutes after the pulse. The following gamma spectra were collected: three 5-minute spectra, three 10-minute spectra, three 15-minute spectra, two 30-minute spectra, and three 60-minute spectra. The durations of the counts were targeted to approximate the halflives of the isotopes being analyzed in that time slice. The detector used was a $68 \%$ relative efficiency HPGe detector, previously calibrated using standard methods. It was operated by the Genie 2000 software package from Canberra Industries. The first counts were on Shelf 10, 4.5 inches from the detector face. The sample was moved to Shelf 5, 2 inches from the detector face, as the dead time dropped to 5\%. As the dead time again reached $5 \%$ the sample was moved to Shelf 3,1 inch from the detector face. 
PNNL-20141

\subsubsection{Gamma Acquisition by High Purity Germanium Detector at PNNL}

Gamma acquisition was performed at PNNL with several single-crystal HPGe detectors with relative efficiencies ranging from $40 \%$ to $105 \%$. These detectors were operated by either APEX Gamma or Genie VMS (Canberra Industries). The calibrated geometries were on the detector face, or 5 or $10 \mathrm{~cm}$ distant from the face. Upon arrival at PNNL, fluence wires had to be first unpackaged to allow separation and placement in individual plastic vials to match previously calibrated detector geometry. Filters and fluence wires were counted in various calibrated geometries for times ranging from 10 minutes to 10 hours, depending on the characteristics of the particular sample. Counting of the samples continued for 1 week after each pulse. Specific information on count geometry, duration, and calibration files are provided with each spectrum.

\subsubsection{Gamma Acquisition by Direct Simultaneous Measurement at PNNL}

The DSM detector system was developed at PNNL and is an array of three HPGe crystals connected in coincidence. The DSM system has three HPGe detectors, two on top and one on bottom. The detectors on top are a planar p-type detector and a semi-coaxial N-type detector. The planar detector (relative efficiency 20\%) has a diameter of $70 \mathrm{~mm}$ and a thickness of $20 \mathrm{~mm}$; its face is $6 \mathrm{~mm}$ from the Be window. The semi-coaxial detector (relative efficiency 140\%) has a diameter of $80 \mathrm{~mm}$ and a thickness of $80 \mathrm{~mm}$. The semi-coaxial detector is located $10 \mathrm{~mm}$ from the back of the planar detector, or $36 \mathrm{~mm}$ from the Be window. The bottom detector (relative efficiency 90\%) is a p-type semi-coaxial crystal. Detection efficiency and dead time can be optimized by adjusting the relative spacing of the detectors. The sample filter inside Tedlar® is mounted in a card geometry and placed $1 \mathrm{~cm}$ from the front face of both detector cryostat faces. This system uses an XIA dgf4c electronics package, which allows list mode data of the energy and synchronized time of each event. The data are parsed into files to create time slice histograms and analyze peaks and coincidence using a PNNL-developed code. The detector system was calibrated for energy and efficiency using standard methods. 
PNNL-20141

\subsection{Data Analysis}

The purpose of data analysis for this work was to verify the quality of the collected data. Sample and fluence monitor data were all analyzed using Genie 2000 v. 3.2 software (Canberra Industries). Below are descriptions of data analysis methods used to determine the neutron spectrum and verify data quality.

\subsection{Neutron Fluence Monitors and Observed Spectrum}

The neutron spectrum may be quantified by use of fluence monitors that have activation reactions sensitive to different neutron energies. The reactions observed during reactor pulses are described in Table 3.1. The reaction rate is calculated for each reaction in Table 3.1, and an average fluence was calculated for each pulse. The fluence values calculated from each reaction indicated good agreement, with a standard deviation of less than $10 \%$ for each reactor pulse. Table 3.2 shows the range of values observed in thermal, epithermal, and fission neutron spectrum experiments. The fluence between reactor pulses cannot be directly compared as this value may be highly variable (Payne et. al. 2009). The reactions monitored and fluences observed in the $14-\mathrm{MeV}$ experiments are presented in Table 3.3. The standard deviation between fluence values obtained from different reactions in 14-MeV neutron irradiations was $12 \%$. This is slightly higher than in the pulsed experiments, but nonetheless indicates good agreement between the fluences determined.

Table 3.1. Activation Reactions Observed for Calculation of Neutron Spectrum

\begin{tabular}{lcc}
\hline Reaction & \multicolumn{2}{c}{ Energy Range $(\mathrm{MeV})$} \\
\hline${ }^{63} \mathrm{Cu}(\mathrm{n}, \gamma){ }^{64} \mathrm{Cu}$ & $1.0 \times 10^{-8}$ & $1.7 \times 10^{-7}$ \\
${ }^{58} \mathrm{Fe}\left(\mathrm{n}, \gamma{ }^{59} \mathrm{Fe}\right.$ & $1.0 \times 10^{-8}$ & $1.7 \times 10^{-7}$ \\
${ }^{59} \mathrm{Co}(\mathrm{n}, \gamma){ }^{60} \mathrm{Co}$ & $1.0 \times 10^{-8}$ & $1.0 \times 10^{-4}$ \\
${ }^{197} \mathrm{Au}(\mathrm{n}, \gamma){ }^{198} \mathrm{Au}$ & $1.0 \times 10^{-8}$ & $4.3 \times 10^{-6}$ \\
${ }^{54} \mathrm{Fe}(\mathrm{n}, \mathrm{p})^{54} \mathrm{Mn}$ & 2.3 & 7.4 \\
${ }^{56} \mathrm{Fe}(\mathrm{n}, \mathrm{p}){ }^{56} \mathrm{Mn}$ & 6.0 & 11.0 \\
${ }^{27} \mathrm{Al}(\mathrm{n}, \alpha)^{24} \mathrm{Na}$ & 6.7 & 12.0 \\
${ }^{47} \mathrm{Ti}(\mathrm{n}, \mathrm{p})^{47} \mathrm{Sc}$ & 6.7 & 12.0 \\
${ }^{48} \mathrm{Ti}(\mathrm{n}, \mathrm{p})^{48} \mathrm{Sc}$ & 5.5 & 12.0 \\
\hline
\end{tabular}

Table 3.2. Ranges of Fluence Values Observed in Each Neutron Spectrum

\begin{tabular}{lcccccc}
\hline & \multicolumn{2}{c}{ Thermal Neutron Spectrum } & \multicolumn{2}{c}{ Epithermal Neutron Spectrum } & \multicolumn{2}{c}{ Fission Neutron Spectrum } \\
\cline { 2 - 6 } & Low & High & Low & High & Low & High \\
\hline Thermal & $1.96 \times 10^{14}$ & $2.28 \times 10^{14}$ & $<1 \times 10^{11}$ & & & \\
fluence $\left(\mathrm{n} / \mathrm{cm}^{2}\right)$ & $\pm 3 \%$ & $\pm 3 \%$ & & & & \\
Epithermal & $4.92 \times 10^{13}$ & $6.17 \times 10^{13}$ & $6.02 \times 10^{13}$ & $9.91 \times 10^{13}$ & & \\
fluence $\left(\mathrm{n} / \mathrm{cm}^{2}\right)$ & $\pm 10 \%$ & $\pm 10 \%$ & $\pm 5 \%$ & $\pm 5 \%$ & & \\
Fission fluence & $2.05 \times 10^{13}$ & $2.75 \times 10^{13}$ & $2.04 \times 10^{13}$ & $3.93 \times 10^{13}$ & $1.96 \times 10^{13}$ & $4.11 \times 10^{13}$ \\
$\left(\mathrm{n} / \mathrm{cm}^{2}\right)$ & $\pm 4 \%$ & $\pm 3 \%$ & $\pm 3 \%$ & $\pm 2 \%$ & $\pm 3 \%$ & $\pm 5 \%$ \\
\hline
\end{tabular}


PNNL-20141

Table 3.3. Example of Observed Neutron Fluence for Cd-Shielded 14-MeV Experiments

\begin{tabular}{lcc}
\hline Reaction & Observed fluence $\left(\mathrm{n} / \mathrm{cm}^{2}\right)$ & Error $(\%)$ \\
\hline${ }^{56} \mathrm{Fe}(\mathrm{n}, \mathrm{p})^{56} \mathrm{Mn}$ & $1.06 \times 10^{10}$ & 6 \\
${ }^{65} \mathrm{Cu}(\mathrm{n}, 2 \mathrm{n}){ }^{64} \mathrm{Cu}$ & $8.84 \times 10^{9}$ & 2 \\
${ }^{197} \mathrm{Au}(\mathrm{n}, 2 \mathrm{n}){ }^{196} \mathrm{Au}$ & $7.96 \times 10^{9}$ & 3 \\
${ }^{27} \mathrm{Al}(\mathrm{n}, \alpha)^{24} \mathrm{Na}$ & $9.05 \times 10^{9}$ & 2 \\
Average & $9.11 \times 10^{9}$ & 12 \\
\hline
\end{tabular}

A Monte Carlo N-Particle (MCNP) model (not shown) was created from the core deck provided by WSU for position D8. The model represents the neutron spectrum anticipated inside each of the shielding materials used. The model confirms that low-energy neutrons are absorbed to an increasing extent when comparing thermal, Cd-shielded, and boron carbide-shielded neutron spectra.

The MCNP models are purely theoretical and therefore cannot be directly compared to experimental fluence data. In order to make this comparison, the MCNP models were modified by use of the STAY'SL computer code (Perey 1977). The format of STAY'SL input and output files was modified at PNNL and standard libraries were established. Input to the STAY'SL code included the reaction rates for each of the nuclear reactions described in Table 3.1 and Table 3.3 and the MCNP calculations. The STAY'SL adjusted neutron spectra for the WSU core are shown in Figure 3.1. The same corrections were made for the MCNP model of the $14 \mathrm{MeV}$ neutron generator (Figure 3.2).

The initial MCNP for thermal, epithermal, and 14-MeV calculations showed some differences from the measurements that varied considerably for each neutron environment. Typically, the problem was that MCNP did not predict the correct ratio of thermal neutrons to the rest of the spectrum with differences typically on the order of 20 to $30 \%$. However, after spectral adjustment with STAY'SL, all the measured reaction rates showed very good agreement, indicating that the measurements are internally consistent, and they provide confidence in the adjusted neutron spectra.

As the $\mathrm{B}_{4} \mathrm{C}$ shield was fabricated for these experiments, special attention was given to verifying that the shield was performing in a consistent and predictable manner. In the fission energy spectrum experiments with $\mathrm{B}_{4} \mathrm{C}$ shielding, there was excellent agreement between the rates of the various activation reactions, four of which are sensitive to thermal neutrons and five of which are threshold reactions. Results calculated from each of the reactions agree within $10 \%$ and the deviation between theoretical and experimental reaction rates is $4.7 \%$. The total neutron fluence is $6.18 \times 10^{13} \mathrm{n} / \mathrm{cm}^{2}$, with $2.67 \times 10^{13} \mathrm{n} / \mathrm{cm}^{2}$ above $1 \mathrm{MeV}$. Less than one percent of the neutrons are below $0.1 \mathrm{keV}$. These data and their consistency indicate that the boron carbide shield is performing as expected and that the thermal contribution to the overall fluence is minimal. See Figure 3.6 below for further evidence of the quality and consistency of the performance of the boron carbide shield. 
PNNL-20141

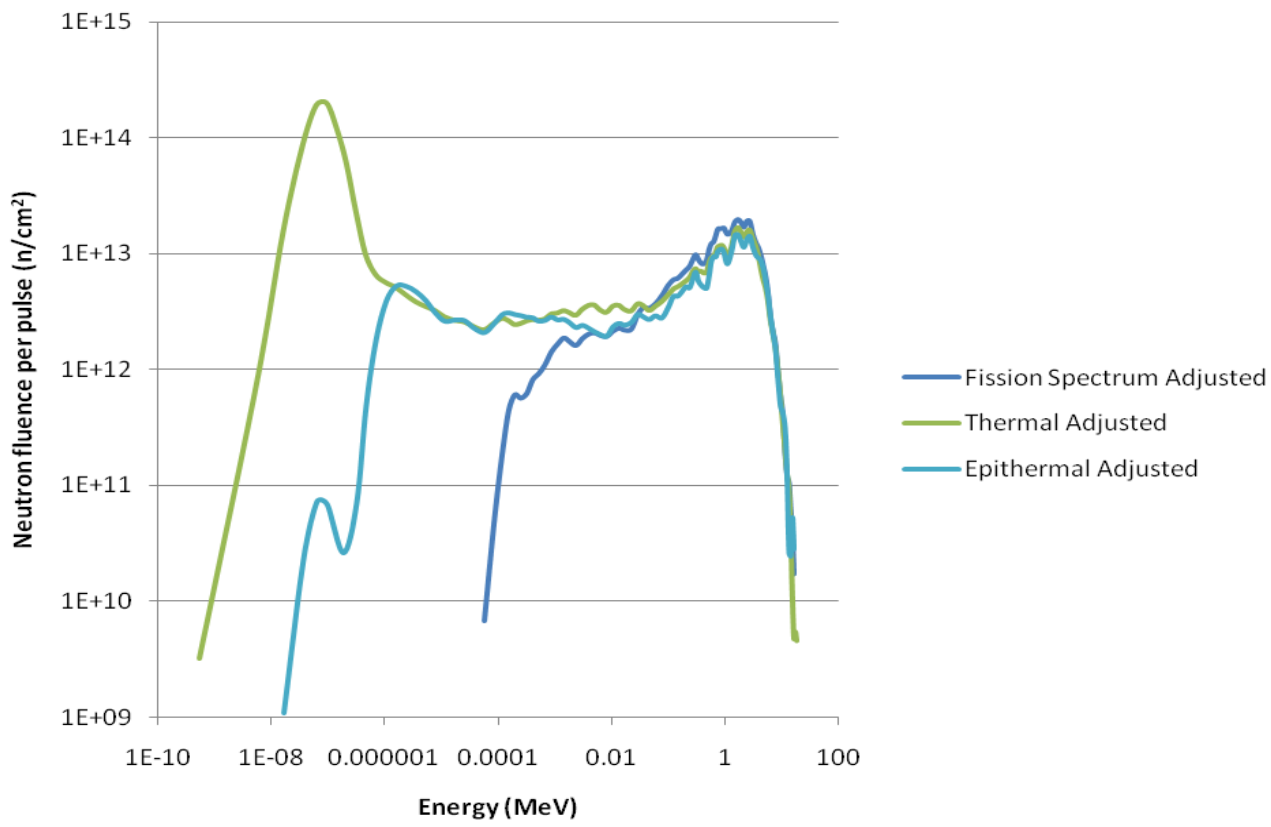

Figure 3.1. Adjusted STAY'SL Model of Neutron Spectrum Within the WSU Core

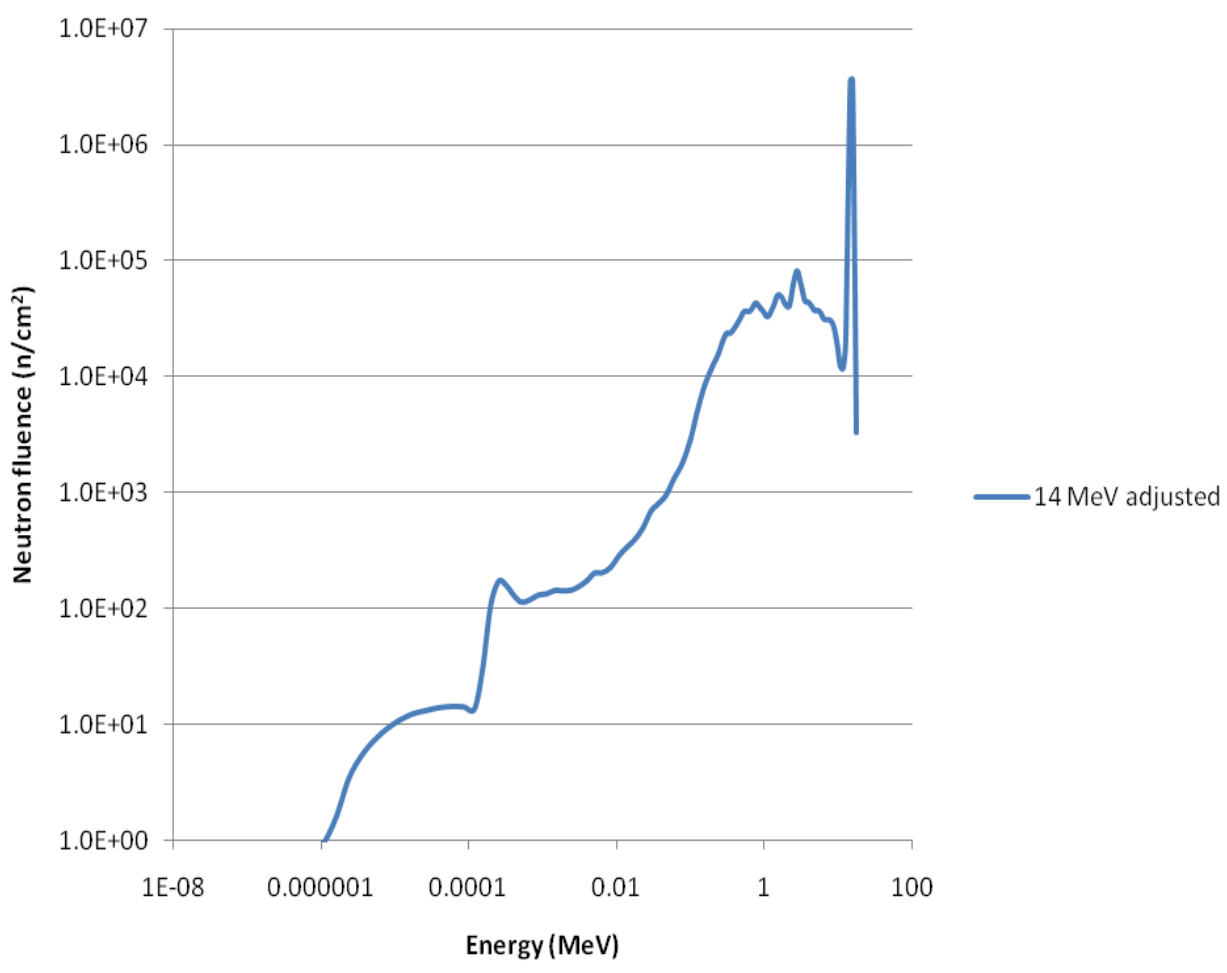

Figure 3.2. Adjusted STAY'SL Model for $14 \mathrm{MeV}$ Neutron Generator 
PNNL-20141

\subsection{Verification of Data Quality}

Sample analysis for both PNNL's and WSU's single-crystal HPGe detectors was performed using Genie 2000 v. 3.2 software (Canberra Industries). Short-lived fission and activation products were identified and quantified. Novel data analysis methods were developed for the time-stamped DSM data. Following data conversion, time slices from the DSM detector system were analyzed using Genie 2000. Data from single-crystal HPGe detectors and the converted DSM data are available on this website. The "How to Access the Data" document provides information on obtaining additional time slices of DSM data. To improve analysis of short-lived isotopes in Genie 2000, a traditional fission product library containing longer-lived isotopes was expanded to include short-lived isotopes with half-lives ranging from 75 seconds to 3 days.

Figure 3.3 provides an example of data from a fission spectrum neutron pulse plotted as fission yield to make it easier to visualize multiple sample nuclides. The number of fissions is calculated by comparing the experimental data with published fission yields from England and Rider (1993). For thermal, epithermal, and fission energy neutron experiments, well-defined double-humped fission product curves were generated. A somewhat smaller number of radionuclides were observed in the 14-MeV experiments (Figure 3.4) because of a lower neutron fluence and fewer resulting fissions, but clusters of radionuclides centered on two masses are still visible.

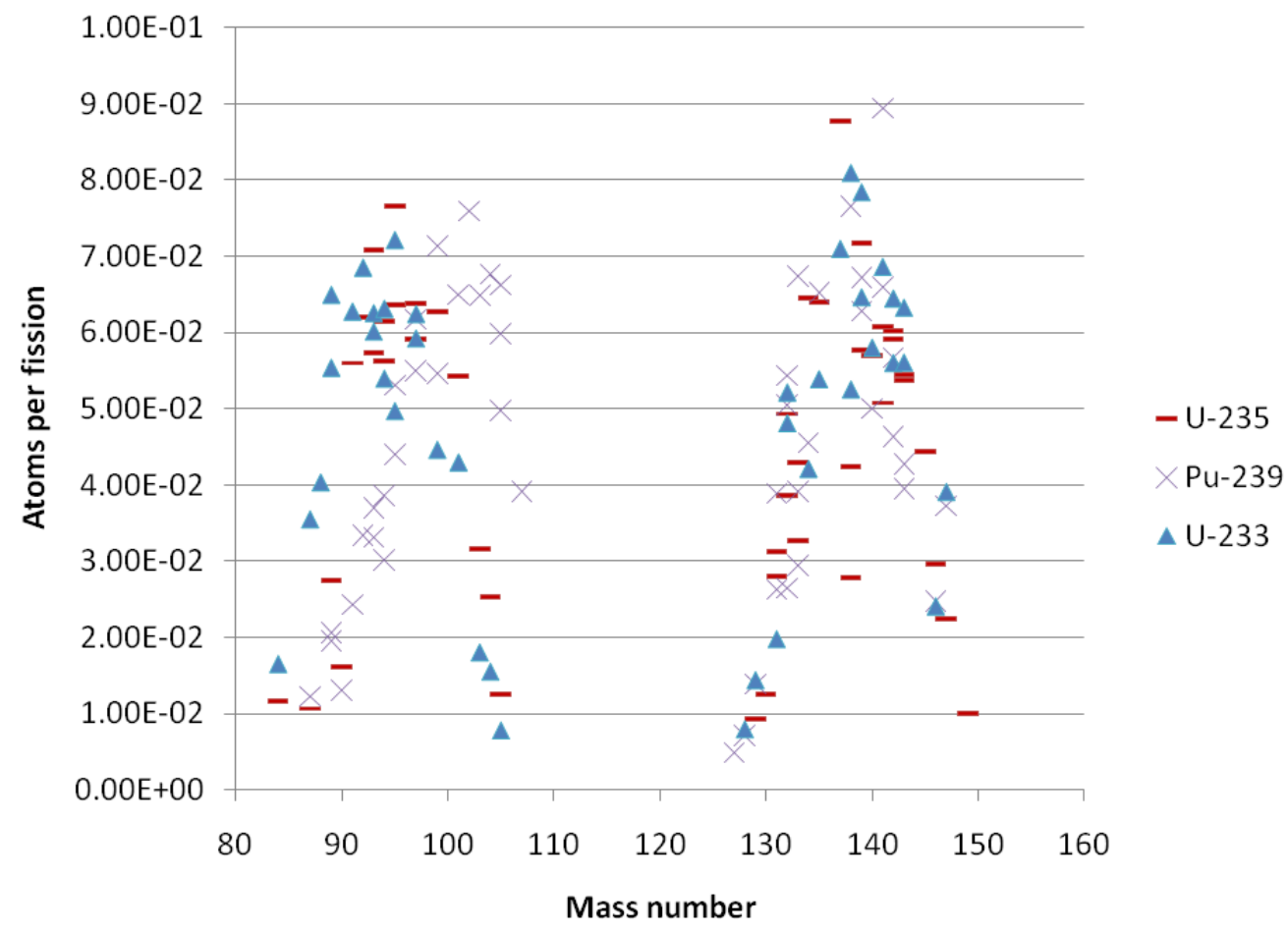

Figure 3.3. Measured Fission Yields in Fission Energy Neutron Experiments 
PNNL-20141

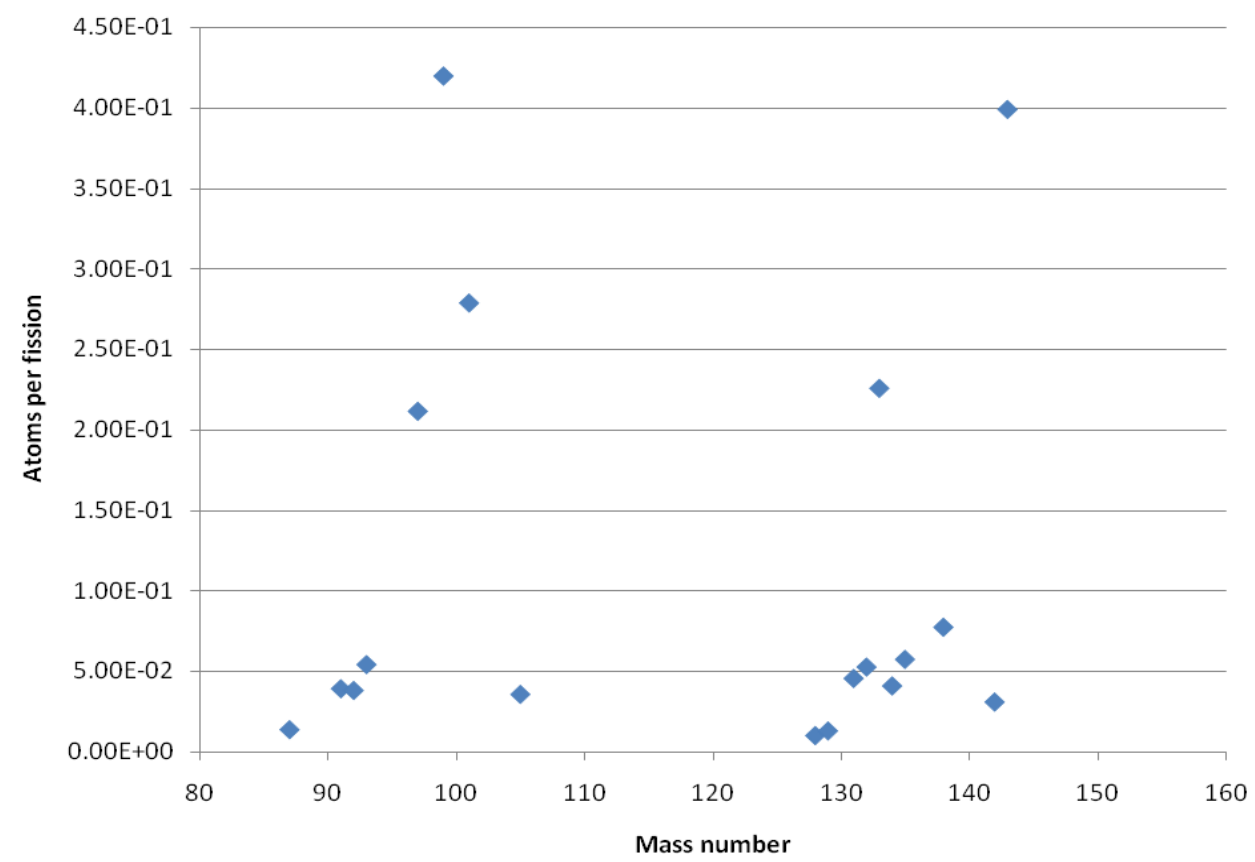

Figure 3.4. Measured Fission Yields in $14-\mathrm{MeV}$ Experiments with ${ }^{238} \mathrm{U}$

There are several methods available to analyze the gamma data for internal consistency, which provides a measure of its quality and reliability. These methods assure that the correct radionuclides have been identified and that the quantification of these radionuclides is accurate. A critical component in quality control is the collection of multiple spectra for each sample.

Verification of radionuclide identification is challenging because of the complexity of the spectra that contain a broad array of fission products at short times. However, by analyzing multiple spectra, the nuclide identification can be determined with greater confidence (Metz et. al. 2009). The activity of a radionuclide identified in multiple spectra can be decay-corrected back to the time of irradiation. When the decay-corrected activity is constant across multiple spectra, the radionuclide has been correctly identified. Figure 3.5 is an example of this type of data analysis for a boron carbide shielded pulse of ${ }^{235} \mathrm{U}$. The radioisotopes ${ }^{91} \mathrm{Sr}$ and ${ }^{92} \mathrm{Sr}$, which have $9.5 \mathrm{~h}$ and $2.7 \mathrm{~h}$ half-lives, respectively, were observed at various times. The data in Figure 3.5 form horizontal lines, which indicate that the correct isotopes have been identified and that the peaks used are free from gamma interferences.

Slow leakage of fission product gases from the Tedlar® was detected by quantifying the gaseous fission products and their daughters over time. This explains the abnormally low values at mass 138 in Figure 3.3. These two data points correspond to ${ }^{138} \mathrm{Xe}$ and its daughter ${ }^{138} \mathrm{Cs}$. Since the containment of the gaseous Xe was incomplete, the resulting production of its daughter was affected. To enable quantitative analysis of gaseous fission products and their daughters, alternative containment designs must be considered. 
PNNL-20141

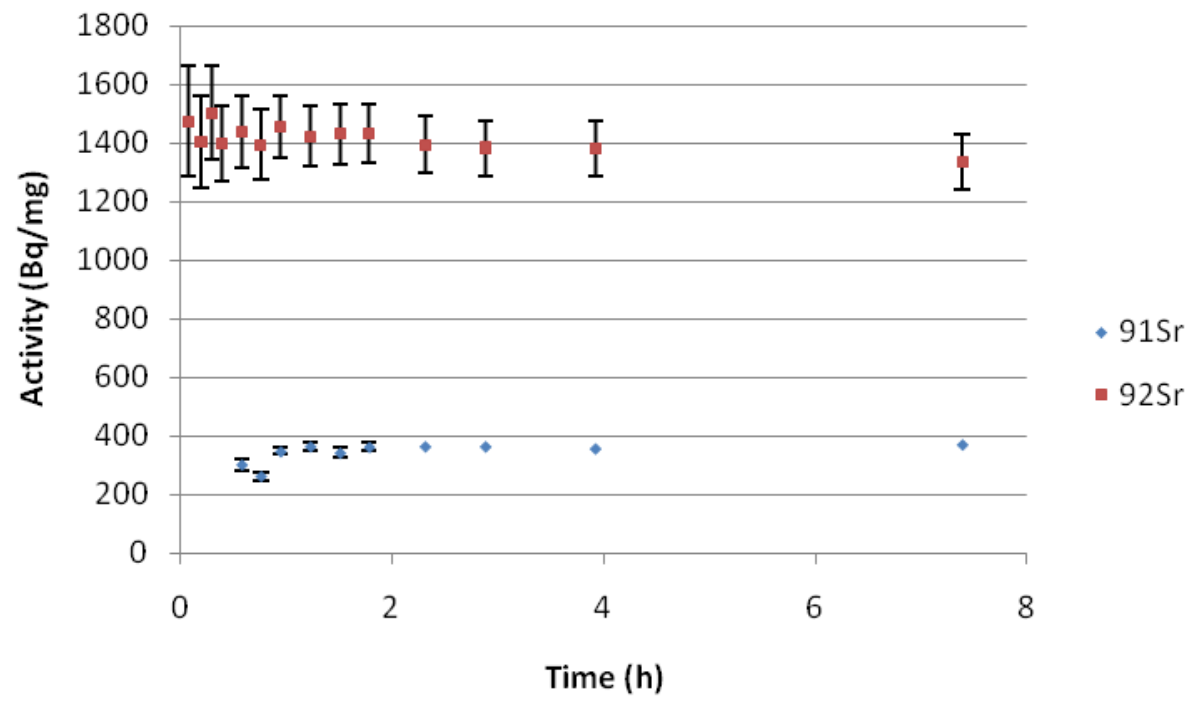

Figure 3.5. Decay-Corrected Counts to Time Zero of ${ }^{91} \mathrm{Sr}\left(\mathrm{t}_{1 / 2}=9.5 \mathrm{~h}\right)$ and ${ }^{92} \mathrm{Sr}\left(\mathrm{t}_{1 / 2}=2.7 \mathrm{~h}\right)$ at Various Times After Irradiation of ${ }^{235} \mathrm{U}$ Under Boron Carbide.

Once the various radionuclides have been identified and quantified according to the procedures above, data can be plotted as fissions/ $\mu \mathrm{g}$ vs. mass. Plotting the data in this way provides an additional mechanism to verify data quality. To generate the plots, experimental data is compared to published fission yields (England and Rider 1993) and the number of fissions generated is calculated from each radionuclide quantified. The number of fissions generated should be constant and independent of the nuclide used in the calculations. Figure 3.6 is an example of a fissions $/ \mu \mathrm{g}$ plot for an irradiation of ${ }^{239} \mathrm{Pu}$ under $\mathrm{B}_{4} \mathrm{C}$. Individual nuclides are represented by points, with blue diamonds showing data collected at WSU and red triangles representing data collected at PNNL. The corresponding colored lines are the average of the respective data set. Data collected at both locations is clustered around a central value with errors in the range of 10 to $15 \%$. Comparison of the number of fissions calculated from each data source (PNNL vs. WSU) and MCNP modeling provides further confidence of data validity since all numbers agree within a few percent. These statistics are typical of all the experiments performed. The data in Figure 3.6 show a high degree of internal consistency, indicating the high quality of the data and the fact that the boron carbide shield is performing according to expectations. 
PNNL-20141

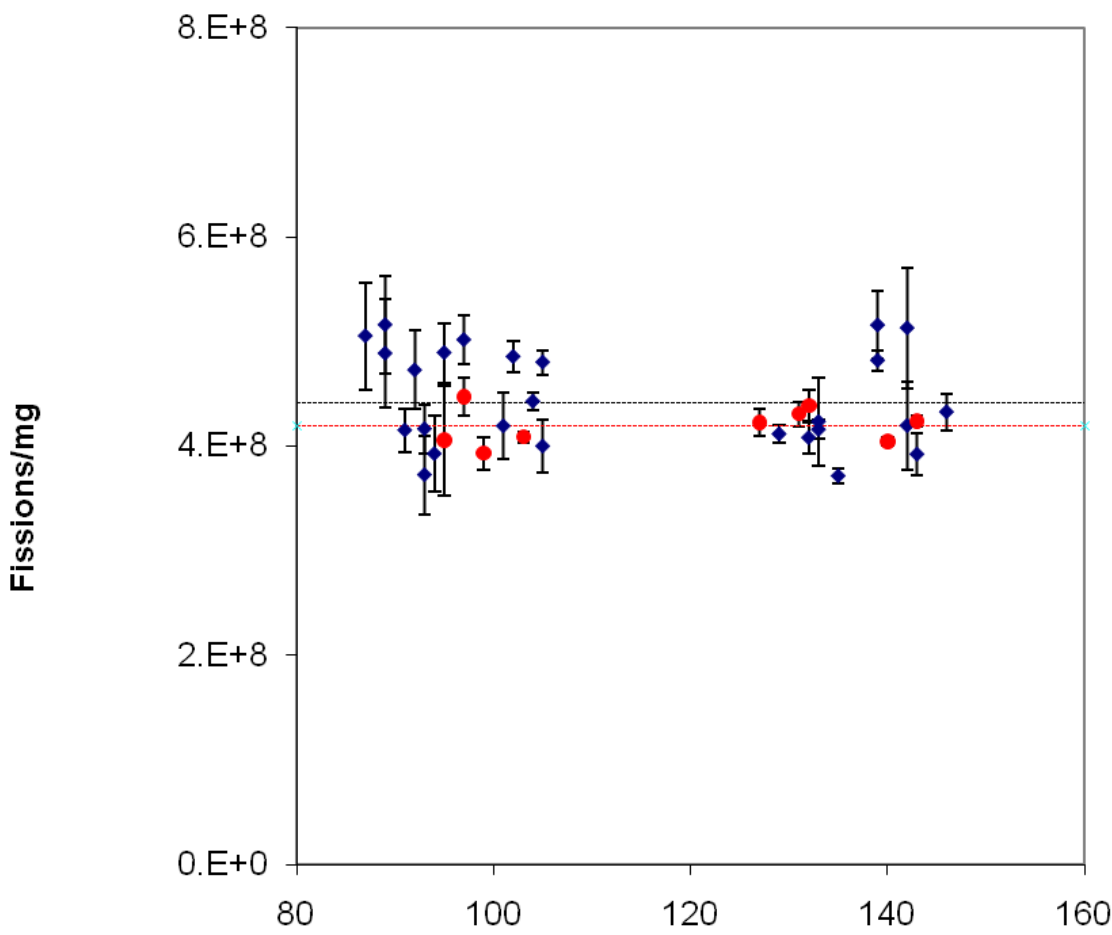

Mass

Figure 3.6. Example of Data Consistency for ${ }^{239} \mathrm{Pu}$ Fission Spectrum Irradiation. Blue diamonds are data collected at WSU immediately after the pulse, with the blue line being the average. Red triangles are data collected after transport to PNNL, with the red line being the average. 


\subsection{Conclusions}

Gamma spectra of the fission products of ${ }^{233,235,238} \mathrm{U},{ }^{237} \mathrm{~Np}$, and ${ }^{239} \mathrm{Pu}$ were collected beginning four minutes after neutron pulses at thermal, epithermal, and fission energy spectra. A wide array of fission products were observed, and the data were shown to be consistent and of high quality. The fission products were in agreement with published values. Fission product gases were lost from the heat-sealed Tedlar ${ }^{\circledR}$ containment. For complete capture of fission product gases for quantitative analysis, alternate containment must be designed. Gamma spectra were also collected following neutron irradiation of ${ }^{238} \mathrm{U}$ using a 14-MeV neutron generator. The sample size and irradiation time were increased for the $14 \mathrm{MeV}$ experiments, but unfortunately only resulted in samples with $\sim 1.5 \times 10^{7}$ fissions or less due to the low neutron fluence of the generator. 
PNNL-20141

\subsection{References}

England TR and BF Rider. 1994. Evaluation and Compilation of Fission Product Yields. LA-UR-943106, ENDF-349, Los Alamos National Laboratory, Los Alamos, New Mexico.

Galy J, B Fogelberg, F Storrer, and H Mach. 2000. "Yields of products from fast neutron-induced fission of ${ }^{233} \mathrm{U}$ measured by means of an Isotope Separator On-Line (ISOL) system." The European Physics Journal A, 8:331.

McLane V, CL Dunford, and PR Rose. 1988. Neutron Cross Sections, vol. 2, Academic Press, San Diego, California.

Metz LA, RF Payne, JI Friese, LR Greenwood, JD Kephart, BD Pierson. 2009. "Experimental Measurements of Short-Lived Fission Products from Uranium, Neptunium, Plutonium and Americium." J. Radioanal. Nucl. Chem. 282(2):373.

Payne RF, JA Drader, JI Friese, LR Greenwood, CC Hines, LA Metz, JD Kephart, MD King, BD Pierson, JD Smith, and DE Wall. 2009. "Neutron Fluence and Energy Reproducibility of a 2-dollar TRIGA Reactor Pulse.” J. Radioanal. Nucl. Chem. 282:59.

Perey FG. 1977. Least Squares Dosimetry Unfolding: The Program STAY'SL. ORNL/TM-6062, Oak Ridge National Laboratory, Oak Ridge, Tennessee.

Turner SE and TG Haynes, III. 2009. "Analytical and Experimental Investigation of Recent Challenges to Neutron Attenuation and the Relationship with Criticality Analyses." Nuclear Technology 169(2):195. 


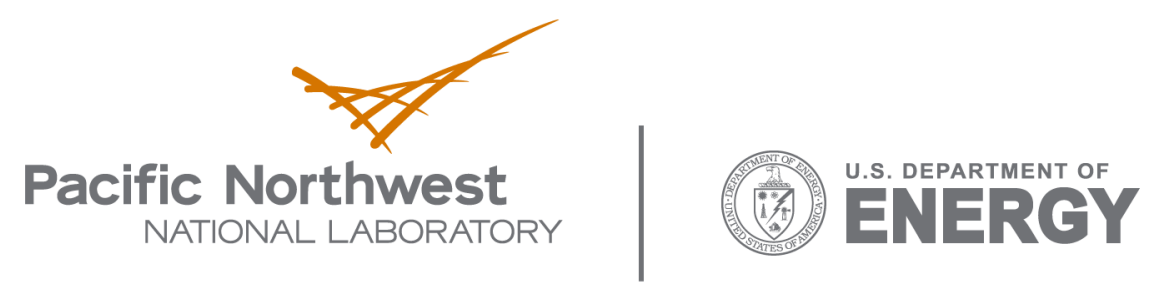

902 Battelle Boulevard

P.O. Box 999

Richland, WA 99352

1-888-375-PNNL (7665)

www.pnl.gov 